\title{
Delegação e controle político das agências reguladoras no Brasil*
}

\author{
Fernanda Meirelles** \\ Rafael Oliva***
}

S UMÁRIO: 1. Introdução; 2. Agências reguladoras: delegação e responsabilização; 3. Mecanismos de controle político das ARIs americanas; 4. Avaliação dos mecanismos de controle político das agências no Brasil; 5. Considerações finais e observações sobre o projeto de lei do novo governo.

SUMmARY: 1. Introduction; 2. Regulatory agencies: delegation and accountability. 3. Political control mechanisms of the American IRAs; 4. Assessing the political control mechanisms of the Brazilian agencies; 5. Final remarks and comments on the new government's law proposal.

Palavras-chave: agência reguladora; regulação; controle político; delegação; accountability.

KEY WORDS: regulatory agency; regulation; political control; delegation; accountability.

A partir de um esforço de sistematização dos mecanismos de controle político previstos no modelo institucional originalmente concebido para as agências reguladoras, este artigo avalia os mecanismos de controle político presentes no arcabouço institucional das agências reguladoras independentes (ARIs) brasileiras e analisa as alterações relacionadas ao controle político introduzidas pelo projeto de lei encaminhado pelo governo ao Congresso em 12 de abril de 2004. Após contextualizar o debate sobre o controle político das ARIs no Brasil, o artigo discute as relações entre delegação

* Artigo recebido em fev. e aceito em maio 2006.

** Advogada, mestre em administração pública e governo pela Eaesp/FGV. Endereço: Rua Cristiano Viana, 163, ap. 151 - Cerqueira César - CEP 05411-000, São Paulo, SP, Brasil. E-mail: femeirelles@hotmail.com.

*** Economista, doutorando e mestre em administração pública e governo pela Eaesp/FGV. Rua Simão Álvares, 479, ap. 124 - Pinheiros - CEP 05417-030, São Paulo, SP, Brasil. E-mail: rafael_oliva@uol.com.br. 
e responsabilização. Em seguida, na busca de um parâmetro para avaliar o modelo brasileiro de agências reguladoras (ARs), identifica os instrumentos de controle político utilizados na experiência americana. Finalmente, avalia a realidade institucional atual das ARIs brasileiras e comenta as contribuições do recente projeto de lei em relação ao controle político das agências.

\section{Delegation and political control of the regulatory agencies in Brazil}

This article systematizes the political control mechanisms provided by the institutional model originally conceived for the regulatory agencies in order to assess the political control mechanisms in the institutional framework of the Brazilian independent regulatory agencies (IRAs) and analyze the political control changes introduced by the law proposed by the government to Congress in April 12, 2004. After putting into context the debate on political control over the Brazilian IRAs, the article discusses the relationship between delegation and accountability. Then, so as to find a parameter for assessing the Brazilian regulatory agency model, it identifies the political control mechanisms used by the American experience. Finally, it assesses the current institutional situation of the Brazilian IRAs and comments on the contribution of the recent law proposal in relation to agency political control.

\section{Introdução}

Em 12 de abril de 2004, o Poder Executivo - por meio do ministro-chefe da Casa Civil da Presidência da República - encaminhou ao Congresso Nacional projeto de lei (PL) versando sobre a "gestão, organização e controle social" das agências reguladoras independentes (ARIs). Como é sabido, ele constitui desdobramento final do esforço de avaliação conduzido pelo novo governo desde o primeiro semestre de 2003 sobre o que, genericamente, tem sido designado como "marco regulatório" das ARIs. Da exposição de motivos (EM) que dá suporte ao PL, assim como do Relatório do Grupo de Trabalho Interministerial (Brasil, 2003) - documento que precedeu a sua formulação - depreende-se que o propósito fundamental do PL é promover o aperfeiçoamento do "modelo institucional das agências reguladoras" (ARs) gestado ao longo do primeiro governo de Fernando Henrique Cardoso, entre 1995 e 1998.

Três objetivos foram a base do esforço de aperfeiçoamento consubstanciado no PL.

Em primeiro lugar, o objetivo de conferir maior uniformidade ao desenho institucional das ARs. Com base na avaliação de que o processo de criação de ARIs a partir de 1997 não teria obedecido a referências comuns, o 
projeto quer instituir um marco legal padrão para a operação do conjunto dos órgãos reguladores, algo que é perseguido, por exemplo, por meio da generalização de dispositivos presentes em algumas das leis de criação das ARIs, mas não em todas, e por meio da imposição de exigências indiferenciadas a todas elas no que respeita a seus processos decisórios internos.

Em segundo lugar, o objetivo de realizar a distinção, entendida como necessária, entre as atribuições de formular políticas, por um lado, e de implementar a regulação, por outro. De acordo com esse entendimento, ao não explicitar as fronteiras que demarcam o campo de prerrogativas dos poderes Executivo e Legislativo (a formulação de políticas) e do ente regulador (implementar a regulação), o modelo vigente teria criado indefinições que, entre outras conseqüências, poderiam ensejar invasões de competências de parte a parte. Caberia ao PL, portanto, remover tais imprecisões.

Finalmente, o PL aponta para uma terceira frente de aperfeiçoamentos, aspecto que nos interessará mais de perto neste artigo. Referimo-nos aqui ao diagnóstico, indicado pelo novo governo, segundo o qual os mecanismos de prestação de contas e responsabilização (accountability) previstos pelo modelo atual das ARIs seriam insuficientes, havendo, portanto, a necessidade do seu fortalecimento.

Com relação à essa preocupação, o PL procura dar dois passos. Por um lado, são sugeridos aperfeiçoamentos no que definiremos aqui como dispositivos de "controle social" da atividade das ARs, isto é, dispositivos que visam ampliar a participação e influência do público em geral nos processos decisórios das ARs. Merece destaque a proposição que prevê que órgãos representativos de consumidores e usuários dos serviços regulados poderão contar com recursos das ARIs para qualificar suas contribuições em processos de consulta pública.

Por outro lado, o PL traz novidades importantes quanto às condições de "controle político" das ARs, os mecanismos de accountability perante os poderes eleitoralmente constituídos, isto é, os poderes Legislativo e Executivo. Nessa direção, dois aspectos especialmente devem ser observados: inicialmente, a recomendação, constante da EM, de que emenda constitucional venha a regulamentar mecanismos de prestação de contas das ARs ao Congresso Nacional; e, adicionalmente, a previsão de que as ARs terão suas atividades disciplinadas por contratos de gestão (CGs), pactuados entre elas e os órgãos do Poder Executivo que lhes estão diretamente vinculados. ${ }^{1}$

\footnotetext{
${ }^{1}$ Por exemplo, nos casos da Anatel e da ANP, os ministérios das Comunicações e de Minas e Energia, respectivamente.
} 
Os impactos que essas alterações virão a produzir sobre a qualidade da atividade regulatória das agências brasileiras são ainda incertos. O debate recente tem sido intenso e avaliações positivas e negativas têm se alternado. Pelo lado positivo, têm sido apontados os ganhos derivados da redução do grau de insulamento dessas novas burocracias, resultante da ampliação das formas de controle. Já pelo lado negativo, tem-se considerado que as alterações propostas, em particular a adoção dos CGs, acabarão por levar à supressão da independência/autonomia das ARs e ao comprometimento da sua performance.

Não é nosso objetivo, porém, opinar nessa controvérsia, sendo mais modestas as pretensões deste artigo. Precisamente, o que se pretende aqui é primeiramente realizar um esforço de sistematização dos mecanismos de controle político previstos no modelo institucional originalmente concebido para as ARs. Com base nessa sistematização buscaremos, então, apreciar de forma exploratória as alterações relacionadas ao controle político das ARs, ora introduzidas pelo PL.

O artigo está estruturado em quatro seções, além desta introdução. Na primeira delas, é desenvolvida uma breve discussão a respeito das relações entre delegação e responsabilização de maneira que o problema teórico que organiza o trabalho seja mais bem definido. Na segunda, e de modo que se tenha um parâmetro a partir do qual se possa avaliar o modelo brasileiro de ARs, reconhecem-se os instrumentos de controle político utilizados na experiência americana - cujo significado paradigmático é freqüentemente destacado. Na seguinte, busca-se considerar a realidade institucional atual das ARIs brasileiras para que, na quarta e conclusiva seção do artigo, sejam desenvolvidos alguns apontamentos sobre o conteúdo do recente PL.

\section{Agências reguladoras: delegação e responsabilização}

A questão concernente à necessidade e à conveniência de que sejam criados mecanismos institucionais por meio dos quais os poderes eleitoralmente constituídos possam realizar o controle político das agências reguladoras se inscreve, em termos teóricos, na discussão sobre as relações entre representação e responsabilização. Mais precisamente, a questão teórica central aqui remonta à problemática weberiana referente ao conjunto de desafios decorrentes da delegação de poderes a burocracias especializadas por governantes escolhidos mediante o processo eleitoral, ou, em termos mais gerais, às relações entre burocracia, política e democracia (Melo, 2001). 
O debate é conhecido. Partindo do reconhecimento de que a evolução das democracias contemporâneas estaria dando lugar à contínua expansão das burocracias, Weber perguntava-se como conciliar os requerimentos de eficiência administrativa e a exigência de que as decisões político-administrativas traduzissem de forma adequada os interesses e preferências dos eleitores. Por um lado, considerava o autor, a progressiva complexificação das funções estatais passou a impor requerimentos de conhecimento crescentes, fenômeno que justificava a racionalização da administração e a delegação de responsabilidades decisórias a corpos técnicos especializados. Por outro, entretanto, na medida em que essa delegação acabaria por corresponder à ampliação do espaço para o exercício da discricionariedade por parte dos burocratas, definia-se o risco de que decisões administrativas viessem a não espelhar as preferências políticas dos representantes eleitos, frustrando-se com isso a expectativa de que os interesses dos eleitores pudessem ser adequadamente concretizados em políticas públicas.

Da perspectiva weberiana, a solução para o problema da responsabilização política dos burocratas corresponderia à constituição de burocracias qualificadas e obedientes a princípios de honra. Conforme aponta Melo (2001:60), de acordo com essa visão, "o interesse público estaria garantido à medida que o conhecimento técnico-científico e seus agentes legítimos - os especialistas credenciados pelo emergente regime de profissões - prevalecessem na condução da coisa pública". Isto é, tendo sido assegurada a "profissionalização" das carreiras, potenciais desvios de representação seriam minimizados, já que o exercício de responsabilidades decisórias autônomas por burocracias especializadas haveria de atender, pela sua "correção técnica", o interesse público. A responsabilização política das burocracias, em suma, seria alcançada ex ante, por meio de mecanismos de recrutamento e seleção.

Desde a sua primeira formulação, porém, a idéia de que o controle político das burocracias poderia ser atingido com base em um projeto de "racionalização das burocracias" ou, em outros termos, na sua "despolitização", não se viu livre de objeções críticas (Melo, 2001:60). Em especial, o suposto de que decisões administrativas seriam redutíveis a uma suposta dimensão "técnica" foi particularmente rejeitado no plano teórico, para o que é suficiente relembrar o clássico Habermas (1975) ou observar, na literatura recente em ciência política, o crescimento da atenção concedida à relação entre burocratas e políticos eleitos, algo particularmente estimulado pela emergência de modelos do tipo principal-agent. $^{2}$

\footnotetext{
${ }^{2}$ Cf., por exemplo, Wood e Waterman (1994).
} 
Tal rejeição, porém, não se limitou ao plano teórico, tendo também se expressado no desenho concreto das instituições político-administrativas. Retornando ao objeto específico deste artigo, é conveniente remarcar que nos EUA o processo de constituição de burocracias especializadas designadas para a regulação de setores específicos de atividade econômica - agências reguladoras - compôs capítulo especial da reflexão político-institucional empreendida naquele país sobre as relações entre burocracia e democracia.

Dados os limites deste artigo, seria impensável empreender a reconstrução dos debates que cercaram a história das agências reguladoras independentes americanas. O ponto a assinalar, não obstante, é que a despeito da influência exercida pela perspectiva wilsoniana quando do surgimento das primeiras ARIs ainda no século XIX - pela qual se afirmava a necessidade e a possibilidade da separação entre administração pública e política - , as sucessivas reconfigurações do marco institucional das agências americanas ao longo do século XX acabariam por afirmar de forma recorrente um não-consentimento com o total insulamento dessas burocracias diante do poder político eleitoralmente constituído (Shapiro, 1997).

Vale notar, a propósito, que mesmo no momento de maior proeminência do Progressive Movement, liderado por Woodrow Wilson e Theodore Roosevelt, não se pretendeu imputar à noção de "independência" alcunha originalmente atribuída às ARIs - o sentido de proteção diante das possíveis influências dos poderes políticos. Diferentemente, e conforme explica o autor, por agências independentes se pretendia designar órgãos especializados nos quais a escolha dos quadros dirigentes deveria ocorrer de maneira a não produzir uma situação de controle absoluto por um dos dois partidos políticos majoritários. Nas palavras de Shapiro (1997:279), "to the progressives who invented the independent regulatory commissions, what 'independent' meant was clear - it meant independent of control by a single political party".

Dois momentos, especialmente, testemunham a preocupação, nos EUA, de como submeter a atividade das ARIs a formas de supervisão e controle político por parte dos poderes eleitoralmente constituídos, momentos que sinalizam o abandono de uma concepção de administração pública baseada na ampla autonomia de burocracias tecnicamente especializadas (Sunstein, 2004:201).

O primeiro deles está mais claramente localizado na década de 1960, período em que o Congresso americano busca ampliar a supervisão das ativi- 
dades regulatórias, principalmente reforçando, sob a inspiração do Administrative Procedures Act, de $1946,{ }^{3}$ o conjunto de controles procedimentais dentro dos quais o rule-making deveria ser conduzido, buscando limitar "a discricionariedade administrativa mediante um maior detalhamento de prazos, procedimentos e instruções sobre implementação" (Sunstein, 2004:134).

O segundo momento, por seu turno, corresponde às décadas de $1970 \mathrm{e}$ 1980 quando, na sucessão dos governos Nixon, Ford, Carter e Reagan, o Poder Executivo passa a editar decretos com o objetivo de exercer maior controle sobre o processo regulatório. As medidas adotadas no período assumiram contornos variados mas, sem nenhuma dúvida, a principal iniciativa implementada nessa direção foi a concentração de competências de supervisão das atividades das ARIs no Office of Management and Budget (OMB), levada a cabo por meio das Executive Orders $n^{0}$ 12.291 e n⿳0 12.498 (Sunstein, 2004:156).

Não é ocioso observar que os dois ciclos de ampliação de mecanismos de controle político que compuseram parte relevante da evolução das ARIs nos EUA foram impulsionados por circunstâncias e motivações distintas. A expansão da supervisão congressual a partir dos anos 1960, por exemplo, é entendida por Sunstein (2004:175) como resultado de um "desejo de assegurar a execução das leis da regulação", evitando a captura dos reguladores, em um momento no qual começava a se configurar, por força da emergência de novas correntes teóricas (como a escola de Chicago), uma percepção negativa quanto à capacidade das ARIs de atuar em conformidade com o interesse público. $\mathrm{O}$ fortalecimento da supervisão pelo Executivo, por outro lado, foi freqüentemente interpretado como sintoma do "ardor anti-regulatório" característico da virada entre as décadas de 1970 e 1980, algo que se teria somado às intenções de conferir maior coordenação e unidade à administração pública federal (Sunstein, 2004:158).

\footnotetext{
${ }^{3}$ Segundo Breyer e colaboradores (1998), o Administrative Procedure Act (APA) nasceu como um compromisso entre defensores e críticos do New Deal no intento de responder à questão da discricionariedade administrativa, que começa a ser entendida como um problema no cenário americano. A principal característica do APA é a sistematização de regras para a tomada de decisão administrativa, de caráter normatizador ou adjudicatório. No caso de normatização pela agência (decision-making), requer-se a publicação prévia da regulação proposta, seguida de oportunidade de manifestação pelos possíveis interessados. Quanto à adjudicação, o APA prevê a realização de audiências conduzidas por juízes administrativos independentes. Outra contribuição marcante do APA foi o estabelecimento de regras quanto à possibilidade, momento, forma e escopo da revisão judicial, que deverá verificar não apenas se as leis relevantes foram observadas, como também se a atuação da agência foi "arbitrária, caprichosa ou abusiva" (Breyer et al., 1998:22-24).
} 
A despeito das controvérsias sobre os fundamentos que impulsionaram a cada tempo os eventos citados, o que se pode derivar é que, nos EUA, o controle político e a responsabilização das agências andaram pari passu com o processo de delegação de competências regulatórias, alimentando, portanto, a atualidade da problemática atinente às relações entre burocracia, representação e democracia.

\section{Mecanismos de controle político das ARls americanas}

Esta seção apresenta uma breve sistematização dos mecanismos por meio dos quais os poderes Legislativo e Executivo americanos têm buscado exercer o controle político - ou responsabilização/accountability política - das ARIs nos EUA. Vale, porém, destacar dois pontos a fim de que os objetivos dessa exposição fiquem mais bem definidos.

Em primeiro lugar, não se tem a intenção de avaliar a eficácia com que os mecanismos de controle político das ARIs têm sido, ou foram, de fato utilizados na experiência americana. Embora seja temática relevante na literatura recente em ciência política, não se pretende indagar aqui se as modalidades de political accountability instituídas pelos poderes eleitoralmente constituídos têm se mostrado capazes de assegurar a responsividade das agências em face das preferências dos political principals, ou se, de uma outra perspectiva, têm produzido efeitos positivos ou negativos sobre a qualidade da regulação. ${ }^{4}$ Diferentemente, a intenção desta seção é apenas a de reconhecer o leque de mecanismos de controle político mobilizado nos EUA, de forma que se disponha de algum

\footnotetext{
${ }^{4}$ No que se refere aos trabalhos orientados para a avaliação da efetividade dos mecanismos de controle político das ARIs pelo Congresso americano, contribuição de extrema relevância foi oferecida por McCubbins e Schwartz (1984), por meio da conhecida distinção entre mecanismos de controle do tipo "patrulha de polícia" e "alarme de incêndio". Segundo os autores, essas burocracias encontravam-se efetivamente sujeitas ao controle político do Congresso americano, no entanto não por meio das formas associadas à então denominada "patrulha de polícia", que corresponderiam às modalidades de monitoramento sistemático e permanente das atividades regulatórias. Segundo McCubbins e Schwartz, o Legislativo americano dispunha de formas de controle menos aparentes, menos custosas, porém mais eficazes do que a supervisão direta por meio de relatórios e auditorias, as quais configurariam o exercício do controle pela modalidade de "alarme de incêndio". Segundo essa abordagem, os políticos realizariam a political accountability das ARIs com base nos sinais e denúncias fornecidos pelos grupos de interesse da base parlamentar os quais desencadeariam uma reação ex post dos políticos que poderia envolver, inclusive, o controle dos recursos que lhes seriam destinados.
} 
parâmetro ante o qual se possa contrapor o conjunto de dispositivos que integram o marco institucional das agências brasileiras.

O segundo ponto a observar é de natureza metodológica. Aqui cabe notar que para a exposição das modalidades de controle político das ARIs americanas mostrou-se necessário optar por uma das taxionomias disponíveis na literatura segundo as quais esses mecanismos são classificados, evitando-se o esforço - desnecessário, dados os objetivos do artigo - de coleta e organização das disposições legais que lhes deram origem. Neste particular, a escolha por nós realizada recaiu sobre a classificação sugerida por Kiewiet e McCubbins (1991) na qual os autores classificam os mecanismos de controle em quatro tipos fundamentais: desenho contratual; triagem e seleção; controle institucional; e monitoramento e prestação de contas.

As razões dessa escolha em larga medida derivam das preocupações de Calvert, McCubbins e Weingast (1989), de acordo com as quais seria equivocada qualquer análise da interação entre políticos e burocratas que não considerasse os diversos momentos do processo de produção regulatória em que são abertas oportunidades de influência pelos políticos eleitos. A utilidade da taxionomia de Kiewiet e McCubbins radica, assim, na circunstância de que todas as fases do rule-making encontram-se por ela contempladas. ${ }^{5}$

O primeiro grupo de mecanismos de controle refere-se, então, ao "desenho contratual" da relação entre políticos e agências. Aqui, quer-se fazer referência à fixação de regras e compromissos específicos, por meio dos quais busca-se estabelecer interesses compartilhados entre agentes e principais de forma a que, ao procurar a consecução de seus próprios objetivos, o agente venha a atuar também de acordo com o interesse do principal. O sucesso desse tipo de controle depende da habilidade dessa contratualização na criação de incentivos à atuação dos agentes em consonância com as preferências dos principais. Assim, as regras que dão suporte à atuação dos burocratas devem ser cuidadosamente formuladas para que premiem a atuação de acordo com as preferências consignadas pelos políticos e punam os casos de discrepância.

"Triagem e seleção" é o segundo tipo de mecanismo de controle à disposição dos políticos eleitos. Nesse caso, os autores apontam para a importância de que, na escolha de seus agents, os principals procurem selecionar aqueles que tenham preferências coincidentes, ou afins, com as suas. Quanto

\footnotetext{
${ }^{5}$ Originalmente a taxionomia de Kiewiet e McCubbins prestou-se à descrição dos procedimentos de controle político dos quais o Congresso poderia fazer uso. Como se verá adiante, contudo, a classificação proposta pelos autores também é capaz de dar conta dos mecanismos de responsabilização política mobilizados pelo Poder Executivo americano.
} 
a esse mecanismo, aliás, Calvert, McCubbins e Weingast (1989) oferecem uma interessante contribuição no tratamento do que definem como "processo de nomeação", 6 em um modelo analítico que engloba, nos moldes do arcabouço principal-agent, os atores do processo e suas preferências. No trabalho desses autores seria possível conceber dois cenários: no primeiro, não haveria incerteza quanto às preferências do agente ou aos resultados das políticas, ao passo que no segundo são incertos tanto o posicionamento do agente quanto os outcomes de suas decisões. Obviamente, na hipótese em que não há incertezas, o controle político sobre a atuação da agência poderia inclusive estar restrito ao processo de escolha e nomeação do burocrata. Bastaria apontar alguém cujos interesses e preferências coincidissem com aqueles encampados pelo órgão político. No entanto, mesmo partindo para uma situação mais realista, permeada de incertezas técnicas e políticas, os autores concluem por uma significativa influência do poder de nomeação no outcome da política adotada pela burocracia. Isto porque ainda que haja margem de atuação discricionária por parte do agente, esta se limita à diferença entre a política adotada e aquela esperada pelos políticos quando da indicação do agente. Essa constatação, de toda forma, não nega a possibilidade de discrepância entre os intentos dos políticos e as decisões de fato tomadas pela burocracia. Mas demonstra que o poder discricionário dos administradores não é tão amplo quanto muitos alegam, e que mesmo em uma situação de incertezas quanto a preferências e resultados, a nomeação de dirigentes exerce um papel significativo no direcionamento político das agências.

A terceira ordem de formas de controle são os mecanismos de controle institucional, tais como poder de veto ou o controle orçamentário. E aqui, mais uma vez, é interessante mencionar o trabalho de Calvert, McCubbins e Weingast (1989), no qual são destacados três mecanismos institucionais de inibição do distanciamento excessivo entre os interesses dos políticos eleitos e a atuação da agência.

Primeiro, e conforme já indicado, o próprio controle orçamentário das agências reguladoras, recurso que, sem nenhuma dúvida, confere grande po-

\footnotetext{
${ }^{6}$ Por "poder de nomeação", Calvert, McCubbins e Weingast (1989:604) entendem uma série de ações que não se restringem à mera escolha de um nome, nos seguintes termos: "The appointement stage should be taken to include any actions that the executive or legislators can take, prior to agency choice, that influence the later goals of the agent or the set of feasible choices available to the agency. Such actions include the structuring of the agency itself, the denomination of its powers and jurisdiction, the specification of administrative procedures to be followed and the type of personnel with which the agency is to be staffed".
} 
der aos políticos eleitos para disciplinar as atividades dessas burocracias, já que implica a possibilidade de conceder ou bloquear os fundos necessários ao exercício do rule-making sob condições adequadas. Quanto a essa modalidade de controle, deve-se atentar que nos EUA as atribuições fundamentais relacionadas à definição e aprovação do orçamento dos diversos órgãos integrantes da administração pública cabem ao Poder Legislativo.

Segundo, Calvert, McCubbins e Weingast apontam para a possibilidade de demissão do agente caso sua atuação se afaste das preferências congressuais. A aplicabilidade desse instrumento, no entanto, ficaria limitada no caso das agências independentes, com mandatos fixos.

O terceiro mecanismo de controle institucional apontado pelos autores, finalmente, é a possibilidade de legislação direta pelo Congresso. Ou seja, uma vez editada uma política ou regulamentação em desconformidade com os interesses dos políticos, estes simplesmente legislam diretamente sobre a matéria, revogando o ato normativo anterior (overruling). De fato, trata-se de uma medida possível, mas difícil de ser implementada. Essa dificuldade depreende-se das circunstâncias que levaram à própria delegação. Sucintamente, são três principais argumentos levantados pela literatura que explicam o fenômeno da delegação: a solução de problemas de impossibilidade de decisão no próprio corpo político em situações em que a definição de uma política, qualquer que seja, tem valor; a transferência dos custos políticos da tomada de decisão para a burocracia (blameshifting); e a necessidade de conferir credibilidade a determinadas políticas, isolando-as da descontinuidade gerada pela sucessão de mandatos eleitorais (Mashaw, 1997; Melo, 2002; Mueller e Pereira, 2002). Assim, para que lance mão da legislação direta sobre a matéria, o Congresso deve rechaçar justamente as razões que o levaram a delegar, superando em pouco tempo um impasse decisório, chamando para si a responsabilidade pelos custos de sua atuação e/ ou enfraquecendo a credibilidade de longo prazo da política.

Vale destacar que, na lógica das análises teóricas de tipo principalagent, os três mecanismos possuem dupla função. Por um lado, podem evitar a continuidade da política escolhida, negando-lhe fundos, revogando-a por meio de um novo ato normativo ou demitindo o agente responsável. Seria uma punição, e, como toda punição, de aplicação ex post. Por outro lado, a mera possibilidade de utilização desses instrumentos pelo Congresso faz com que os burocratas, durante o processo de policymaking, levem em consideração as preferências dos políticos. Trata-se, aqui, de uma forma de controle "latente", consistente na simples ameaça de punição ou ineficácia da política.

Por fim, a classificação de Kiewiet e McCubbins também identifica os instrumentos de monitoramento e prestação de contas, pelos quais se exige 
do agente o compartilhamento de informações e o acesso aos dados internos da organização. As auditorias e processos de investigação são as formas mais conhecidas de exercício de monitoramento direto por parte dos políticos. No entanto, vários autores vêm destacando que a configuração de procedimentos administrativos é um meio efetivo, e menos oneroso, de monitoramento da burocracia (McCubbins, Noll e Weingast, 1987; Bawn, 1995). Em vez de valer-se de instrumentos custosos de supervisão, tais como audiências congressuais e comissões de investigação, os políticos eleitos podem impor determinados formatos procedimentais às agências que garantam a coleta e publicização de informações relevantes; o acesso a essas informações e a participação de setores componentes do jogo de forças relevantes (McCubbins, Noll e Weingast, 1987). A proposição fundamental é a de que o processo decisório das agências seja mediado por algum tipo de mecanismo de representação de interesses que, justamente, seja capaz de refletir a composição de interesses em cada caso específico.

Todavia, o entendimento do processo administrativo como uma forma de controle eficaz do Congresso sobre as agências governamentais não é pacífico. Balla e Wright (2001), por exemplo, apontam que não há clareza com relação aos critérios a serem obedecidos para a composição de tais estruturas representativas, nem quais forças teriam espaço nessas estruturas. Aliás, conforme ressalva Mashaw (1997:121), a concessão de vantagens a certos interesses em um determinado procedimento administrativo não garante que esses sejam os interesses dos grupos que os legisladores procuraram beneficiar. De qualquer forma, ainda que imperfeito, o processo administrativo tem o condão de facilitar tanto a "patrulha de polícia", por produzir informações para melhor supervisão e monitoramento pelo Congresso, quanto o "alarme de incêndio", ao permitir o acompanhamento e participação de grupos de interesse que poderão acionar os políticos em caso de conduta indesejada.

Nos EUA, a iniciativa maior no que concerne à introdução de procedimentos administrativos que disciplinassem a atuação das ARIs coube, historicamente, ao Poder Legislativo, algo que teve sua expressão mais evidente na edição do APA em 1946. De toda maneira, convém apontar que a ampliação das competências do OMB ao longo da década de 1980 deslocou para o Poder Executivo capacidades importantes de controle político das ARIs por meio de mecanismos procedimentais. Isso ocorreu por meio da delegação, ao OMB, das funções de: avaliar o conjunto dos "programas regulatórios" de todas as agências, com o fim de identificar a existência de eventuais duplicações de esforços entre os diferentes órgãos; requerer, das ARIs, análises do impacto regulatório (regulatory impact analysis, RIA), isto é, estimativas dos custos implícitos em cada norma em estudo, condicionando a sua aprovação à de- 
monstração de que os benefícios a serem produzidos por esses regulamentos justificam a sua implementação; e requerer das ARIs a publicação antecipada dos regulamentos que se pretende encaminhar, tornando disponíveis todos os documentos relevantes (estudos e material de apoio) utilizados na sua confecção (Yataganas, 2001).

\section{Avaliação dos mecanismos de controle político das agências no Brasil}

Tendo por referência a taxionomia proposta por Kiewiet e McCubbins procuraremos, nesta seção, avaliar se o marco legal das agências reguladoras brasileiras comporta, na sua formulação original, mecanismos de controle político.

Mais uma vez, é conveniente observar que a análise a ser desenvolvida tem uma preocupação eminentemente institucional, não se pretendendo alcançar aqui qualquer diagnóstico sobre a efetividade dos dispositivos existentes. A nossa intenção é apenas reconhecer o conjunto de mecanismos de controle político disponíveis tendo por base as leis que regem as agências reguladoras relacionadas a mercados de infra-estrutura, quais sejam, a Agência Nacional do Petróleo (ANP) (Lei no 9.478/1997 e Decreto nº 2.455/1998), a Agência Nacional de Energia Elétrica (Aneel) (Lei no 9.427/1996 e Decreto no $2.335 / 1997$ ), a Agência Nacional de Telecomunicações (Anatel) (Lei $n^{0}$ 9.472/1997 e Decreto no $2.338 / 1997$ ) e a Agência Nacional de Transportes Terrestres (ANTT) (Lei $n^{\circ}$ 10.233/2001 e Decreto $n^{0}$ 4.130/2002). ${ }^{7}$

De início, é importante assinalar que a considerável uniformidade entre os dispositivos que regem a estruturação das agências reguladoras permite que os mecanismos de controle político das agências sejam tratados de forma agrupada, conforme a classificação de Kiewiet e McCubbins. De toda maneira, quando se mostrar necessário, especificidades próprias a cada uma das agências serão destacadas.

\section{Desenho contratual}

Retomando a idéia de que esse tipo de controle se dá pelo estabelecimento de regras que compatibilizem os interesses de delegantes e delegatários, entendemos adequado enquadrar a celebração de contratos de gestão entre as

\footnotetext{
${ }^{7}$ Em cada caso, leis de criação e decretos de aprovação do regulamento interno das agências.
} 
agências reguladoras e ministérios como um mecanismo de desenho contratual afeito à viabilização do controle político das primeiras pelo Poder Executivo. Nas leis de criação das agências acima indicadas, porém, a utilização desse mecanismo de controle político foi restringida à Aneel, não tendo sido estendida aos demais órgãos reguladores dos setores de infra-estrutura.

Conforme determina o Decreto $\mathrm{n}^{\mathrm{O}}$ 2.335/1997, o contrato de gestão tem por finalidade servir como "instrumento de controle da atuação administrativa da autarquia [a Aneel] e do seu desempenho", cabendo-lhe especificar objetivos, metas, prazos e indicadores de desempenho a serem observados pela agência, e responsabilizando os signatários pelo seu cumprimento.

Um ponto a notar aqui é que a caracterização do contrato de gestão como um mecanismo de controle político depende particularmente do seu conteúdo, algo que é certamente mais decisivo que a sua mera previsão legislativa. De fato, o grau de detalhamento e o enfoque (substantivo ou procedimental) do contrato de gestão são elementos-chave para a compreensão de seu papel na relação entre reguladores e políticos. No caso específico da Aneel, entretanto, nota-se que mesmo quando o legislador tenta indicar o conteúdo do contrato de gestão, ele o faz de maneira muito genérica, limitando-se a afirmar que os objetivos e metas de desempenho a serem incluídos no CG devem fazer referência a três elementos: "a regulação econômica do setor de energia elétrica"; "a fiscalização e qualidade dos serviços de energia elétrica"; e "a efetividade no uso e na oferta de energia elétrica".

\section{Triagem e seleção}

Conforme alertado pela literatura americana, o processo de seleção e nomeação dos quadros das agências é um dos principais campos de influência dos políticos sobre as agências. Quanto a isso, deve ser notado que todas as leis de constituição das ARs, assim como a Lei no 9.986, de 18 de julho de 2000 — que dispõe sobre a gestão de recursos humanos nas agências reguladoras -, estabelecem que as diretorias dos órgãos reguladores devem ser compostas por membros nomeados pelo presidente da República mediante aprovação pelo Congresso; e que o diretor-presidente (ou diretor-geral) das agências deve ser escolhido pelo presidente da República entre os membros já aprovados.

O desenho institucional das ARs no Brasil, portanto, teve uma preocupação clara em manter o poder de triagem e seleção da diretoria das agências nas mãos de agentes eleitoralmente constituídos. Todavia, é clara a preponderância do Executivo nesse processo, a quem cabe a indicação de todos os diretores e a definição do diretor-presidente. Ao Senado, cumpre 
aprovar ou negar os nomes indicados pela Presidência para a diretoria das agências. $^{8}$

\section{Controles institucionais}

Na seção anterior, foram destacados os três principais mecanismos institucionais de controle discutidos no caso americano: controle orçamentário, possibilidade de demissão de diretores e revogação da decisão da agência por meio de legislação direta.

Quanto ao controle orçamentário, as leis de criação das ARs buscaram criar condições para sua autonomia financeira, prevendo-se em cada caso fontes de recursos independentes da dotação orçamentária da União. No entanto, o que poderia ser visto como um sinal de maior independência das agências em relação ao Executivo e ao Legislativo encontra-se sujeito a ter seus efeitos limitados. Isso porque, os recursos advindos de suas fontes próprias também são contabilizados como parte do orçamento geral da União, e, como tal, tornam-se objeto de controle, e potenciais contingenciamentos, pelo Ministério do Planejamento (Melo, 2002:280). Entende-se, portanto, que o controle orçamentário também no Brasil configura-se como mecanismo de controle político das agências reguladoras. Vale destacar, porém, que $o$ processo orçamentário no Brasil, diferentemente dos EUA, é fortemente concentrado no Poder Executivo, reservando margens estreitas para a atuação direta do Parlamento (Loureiro, 2001).

O segundo mecanismo de controle institucional consiste na possibilidade de demissão de diretores pelo Executivo ou Legislativo. No caso brasileiro, as leis referentes às ARs estabelecem que a diretoria exerce um mandato fixo, indicando, em princípio, a impossibilidade de demissão dos diretores. No entanto, trata-se de matéria sujeita a um extenso debate jurídico, uma vez que é possível enxergar no art. 84, inciso II, da Constituição Federal, a autorização de que o presidente, exercendo a "direção superior da administração pública federal", interrompa o mandato dos diretores das agências. Caso esse entendimento prevaleça, nota-se novamente a preponderância do Executivo.

Por fim, o controle por meio da legislação direta seria um mecanismo à disposição do Congresso Nacional brasileiro, uma vez que tem por fundamento sua atribuição constitucional de órgão legiferante. É de se ponderar, no en-

\footnotetext{
${ }^{8}$ Caberia questionar, contudo, se o Senado vem de fato exercendo suas atribuições, questionamento plausível já que desde a constituição das agências não foi registrado veto a qualquer um dos nomes indicados pelo presidente.
} 
tanto, que esse mecanismo de controle político ex post requer um grau de coesão e de agilidade para revogação da decisão da agência raro em parlamentos multipartidários como o brasileiro.

\section{Monitoramento e prestação de contas}

Os mecanismos de monitoramento e de prestação de contas, conforme sistematizado na seção anterior, podem tanto tomar o formato clássico de auditorias e investigações, quanto serem exercidos por meio de regras procedimentais impostas às ARs.

No primeiro caso, é importante destacar que não há vedação, em qualquer das leis de criação das ARIs, a que o Legislativo exerça as prerrogativas previstas pelo inciso X do art. 49 da Constituição Federal, de acordo com as quais é sua competência exclusiva "fiscalizar e controlar, diretamente, ou por qualquer de suas casas, os atos do Poder Executivo, incluídos os da administração indireta". Vale dizer, do ponto de vista jurídico o modelo das ARIs brasileiras, ao não suscitar qualquer alteração na $\mathrm{CF}$, reafirmou que a fiscalização e controle desses entes são atribuições legítimas do Congresso Nacional. É patente, contudo, que a falta de regulamentação sobre a forma de exercício desse monitoramento pode representar um entrave para a maior atuação dos parlamentares.

Também no modelo brasileiro foram estabelecidas regras procedimentais que permitem maior controle político das ARs. Ressaltam-se, aqui, mecanismos orientados para a publicização das decisões regulatórias, para a realização de consultas públicas, assim como exigências de que as escolhas finais feitas pelo regulador devem ser sustentadas por justificação escrita, pública e racionalmente fundamentada algo que, notadamente, facilita o acompanhamento e o controle da atividade regulatória pelos atores políticos. Ademais, é obrigatória a comunicação prévia à Casa Civil da Presidência da República em caso de audiência pública acerca de anteprojeto de lei proposto pela agência. Vale dizer, ainda que haja alguma variabilidade no detalhamento dos procedimentos a serem seguidos por cada agência — variabilidade que, aliás, o recente projeto de lei procura eliminar —, não há dúvida de que se poderia encontrar um arcabouço comum ao qual todas elas estão submetidas e que guarda notáveis similaridades com o APA americano.

Ausência a ser observada é que no marco institucional das agências brasileiras não há mecanismos procedimentais que condicionem a produção regulatória ao desenvolvimento de análises do tipo custo-benefício, exigência cujo controle, nos EUA, é realizado pelo Poder Executivo com o OMB. 


\section{Considerações finais e observações sobre o projeto de lei do novo governo}

A descrição dos mecanismos de controle político previstos nas leis de criação das agências reguladoras brasileiras, tendo como pano de fundo alguns dispositivos constitucionais, permite afirmar que estamos longe de uma situação de isolamento total das agências reguladoras, em que não haveria mecanismos de controle político à disposição do Executivo ou do Legislativo. Conforme se apontou na seção anterior, o modelo institucional brasileiro, tal como ele se encontra definido atualmente, permite a utilização da maioria dos mecanismos de controle político destacados pela literatura americana, ainda que em alguns casos esses mecanismos advenham de interpretações controversas do marco legal das agências - a exemplo do contingenciamento de recursos orçamentários originados de fontes próprias das ARs.

Para além dessa constatação geral, entretanto, cabem observações mais específicas sobre o atual modelo institucional das ARs brasileiras.

Em primeiro lugar, é notável que no controle político das agências foram destinadas atribuições mais restritas ao Poder Legislativo, na comparação com aquelas de que dispõe o Executivo.

Quatro limitações enfrentadas pelo Legislativo brasileiro podem ser especialmente mencionadas: a ausência de sua participação na elaboração de contratos de gestão, o que se observa no caso da Aneel; a restrição à figura do presidente da República de eventual possibilidade de demissão de diretor da AR; a falta de controle sobre o repasse de recursos às ARs, derivada do fato de que na lei orçamentária brasileira cabe ao Legislativo uma função meramente autorizativa (Pereira, 2002:172-174); e a inexistência de regulamentação específica sobre a forma de exercício do poder de monitoramento e fiscalização estabelecido no art. 49 da Constituição Federal. Não é objetivo deste artigo discutir as razões que poderiam explicar o papel desempenhado pelo Congresso diante do Executivo. Poder-se-ia, por exemplo, cogitar a ausência de interesse do Legislativo no controle das agências, ou levantar a hipótese de que os parlamentares exercem alguma forma de controle, mas por meio de influência indireta e de pouca visibilidade junto ao Executivo. Ou ainda questionar se haveria, por parte do Congresso, uma descrença nos mecanismos institucionais de controle das ARs enquanto o orçamento estiver fora do alcance do Legislativo. Deixamos essas indagações, porém, para que sejam investigadas em trabalhos futuros.

Em segundo lugar, destaca-se também a utilização incipiente de mecanismos do tipo "desenho contratual" na political accountability das agências, exceção feita ao estabelecimento ainda localizado de contratos de gestão nos 
termos acima descritos, por meio dos quais seria possível a fixação de regras para o direcionamento da atuação das agências. Deve-se reiterar, porém, que no caso brasileiro o contract design acabou por ficar confinado ao Poder Executivo e, mesmo nesse caso, não se pode dizer que a sua finalidade esteja claramente demarcada pelas disposições legais existentes.

Em terceiro lugar, e pelo lado positivo, atente-se para a enfática previsão de uso de procedimentos administrativos, como consultas e audiências públicas, nas leis de criação de todas as ARs examinadas. De toda forma, não há evidências de que esses canais têm sido efetivamente utilizados como suporte para o exercício de controle da atividade regulatória pelos políticos eleitos.

Diante dessas considerações, que avaliação se poderia fazer das modificações sugeridas pelo PL ora sob apreciação do Congresso Nacional?

Inicialmente, observa-se que o projeto de lei encaminhado ao Congresso apresenta disposições relativas a todos os tipos de controle já discutidos com base na taxionomia de Kiewiet e McCubbins. É interessante notar, no entanto, que muitas delas já estavam previstas nos diplomas legais de cada agência, não tendo sido proposta efetiva alteração das definições preexistentes e, sim, a sua reiteração. Assim, o PL não inova em relação à nomeação da diretoria, aos procedimentos internos das agências, e ao controle orçamentário, mecanismos já presentes no atual arcabouço institucional das ARs.

Não obstante, no que concerne à modalidade que inclui os mecanismos de desenho contratual, é razoável afirmar que o PL trouxe modificações importantes já que, conforme comentado anteriormente, foi generalizado o uso dos contratos de gestão como mecanismo de "acompanhamento da atuação administrativa das agências reguladoras e da avaliação do seu desempenho", algo antes restrito a algumas delas apenas. Note-se, porém, que os contornos precisos do instrumento ainda não foram completamente esclarecidos, mantendo-se, assim, o caráter genérico que o tem marcado, por exemplo, nas leis que dispõem sobre a operação da Aneel. De fato, além de enunciar os objetivos dos CGs, "aperfeiçoar o acompanhamento da gestão, promovendo maior transparência e controle social" e "aperfeiçoar as relações de cooperação da agência reguladora com o poder público, em particular no cumprimento das políticas públicas definidas em lei", o PL pouco avança na identificação do que seriam metas de desempenho dos órgãos reguladores.

Outras alterações promovidas pelo projeto relacionam-se com o quarto tipo de mecanismo de controle já considerado, o monitoramento e a prestação de contas. Aqui, todavia, as mudanças foram de menor envergadura. Por um lado, buscou-se reforçar o mecanismo de monitoramento tradicional por meio do estabelecimento da obrigatoriedade de envio, pelas ARs, de relatórios anuais reportando suas atividades ao ministério vinculado e ao Congresso Nacio- 
nal. Por outro, buscou-se fortalecer também os procedimentos de consulta pública prevendo-se condições mais favoráveis à participação de órgãos representativos dos consumidores, nos termos já apontados na introdução do artigo.

Em segundo lugar, registre-se que o PL acaba por seguir a tradição brasileira de reforçar a preponderância do papel do Executivo no controle da burocracia. Isso fica claro quando se verifica que o contrato de gestão, principal alteração trazida pelo PL, coloca o ministério como o ator central no controle das agências, não prevendo a participação do Parlamento neste instrumento sequer como coadjuvante.

Como terceira e última consideração, no entanto, vale observar que embora o PL não concretize formas de maior envolvimento do Legislativo, a exposição de motivos é bastante explícita ao indicar aos parlamentares essa possibilidade, deixando claro que a forma de sua atuação para o controle político das ARs depende apenas do próprio Congresso. Conforme já apontado na introdução, isso é feito por meio da recomendação, na exposição de motivos, de que o Legislativo promulgue emenda constitucional que discipline formas de monitoramento e fiscalização das agências pelos parlamentares.

Por ora, entretanto, a questão central diz respeito a saber de que forma o Congresso se comportará ante essa oportunidade, isto é, se virá de fato a implementar tal recomendação e por que razões. Vale dizer, se for correta a hipótese de que no momento de concepção do modelo de ARs brasileiras o Legislativo optou por não se imputar atribuições de controle político muito significativas, cabe perguntar se, neste momento, o leque de incentivos que informa o cálculo político dos congressistas é mais favorável à assunção de tarefas desta natureza.

\section{Referências bibliográficas}

ABERBACH, J. D.; PUTNAM, R. D.; ROCKMAN, B. A. Bureaucrats and politicians in Western democracies. Harvard University Press, 1981.

BALLA, S.; WRIGHT, J. Interest groups, advisory committees, and congressional control of bureaucracy. American Journal of Political Science, v. 45, n. 4, Oct. 2001.

BAWN, K. Political control versus expertise: congressional choices about administrative procedures. The American Political Science Review, v. 89, n. 1, p. 62-73, Mar. 1995.

BRASIL. Casa Civil. Câmara de Infra-Estrutura/Câmara de Política Econômica. Análise e avaliação do papel das agências reguladoras no atual arranjo institucional brasileiro - Relatório do Grupo de Trabalho Interministerial. Brasília, 2003. 
BREYER, S. et al. Administrative law and regulatory policy: problems, text, and cases. New York: Aspen Law \& Business, 1998.

CALVERT, R. L.; MCCUBBINS, M. D.; WEINGAST, B. R. A theory of political control and agency discretion. American Journal of Political Science, v. 33, n. 3, p. 588-611, Aug. 1989.

DEMSETZ, H. Why regulate utilities? Journal of Law and Economics, n. 11, p. 55-65, Apr. 1968.

HABERMAS, J. Técnica e ciência como "ideologia". In: BENJAMIN, W. et al. Textos escolhidos. São Paulo: Abril Cultural, 1975.

KIEWIET, R.; MCCUBBINS, M. The logic of delegation: congressional parties and the appropriations process. Chicago: The University of Chicago Press, 1991.

LOUREIRO, M. R. O controle da burocracia no presidencialismo. Burocracia e reforma do Estado. Cadernos Adenauer, v. 2, n. 3, 2001.

MANIN, B.; PRZEWORSKI, A.; STOKES, S. Introduction. Elections and representation. In: PRZEWORSKI, A. et al. Democracy, accountabilty and representation. Cambridge: Cambridge University Press, 1999.

MASHAW, J. L. Greed, chaos and governance. New Haven: Yale University Press, 1997. caps. 5 e 6.

MCCUBBINS, M. D.; NOLL, R. G.; WEINGAST, B. R. Administrative procedures as instruments of political control. Journal of Law, Economics and Organization, v. 3, n. 2, p. 243277, Fall 1987.

-; SCHWARTZ, T. Congressional oversight overlooked: police patrols versus fire alarms. American Journal of Political Science, n. 2, p. 165-179, 1984.

MELO, M. A. A política da ação regulatória. Revista Brasileira de Ciências Sociais, v. 16, n. 46, p. 55-68, jun. 2001.

—. As agências regulatórias: gênese, desenho institucional e governança. In: ABRUCIO, F.; LOUREIRO, M. R. (Orgs.). O Estado numa era de reformas: os anos FHC. Brasília: Seges-MP, 2002. p. 247-305.

MUELLER, B.; PEREIRA, C. Credibility and the design of regulatory agencies in Brazil. Brazilian Journal of Political Economy, v. 22, n. 3, p. 65-88, Sept. 2002.

PEREIRA, M. Políticas públicas, política orçamentária e processo orçamentário no Brasil. São Paulo: Campus, 2002.

SHAPIRO, M. The problems of independent agencies in the United States and the European Union. Journal of European Public Policy, v. 4, n. 2, p. 276-291, June 1997. 
STIGLER, G. The theory of economic regulation. The Bell Journal of Economics and Management Science, v. 2, p. 3-21, 1971.

SUNSTEIN, C. Constitucionalismo após o New Deal. In: Regulação econômica e democracia. São Paulo: Editora 34, 2004.

WOOD, B. D.; WATERMAN, R. W. Bureaucratic dynamics: the role of bureaucracy in a democracy. Boulder: Westview Press, 1994.

YATAGANAS, X. Delegation of regulatory authority in the European Union: the relevance of the American model of independent agencies, 2001. (Jean Monnet Working Paper 3/01) 